\title{
CAMBIO CLIMÁTICO Y PATRONES DE ASENTAMIENTO EN LA VERTIENTE OCCIDENTAL DE LOS ANDES DEL SUR DEL PERÚ
}

\author{
CLIMATE CHANGE AND SETTLEMENT PATTERNS AT THE WESTERN SLOPE \\ OF THE ANDES IN SOUTHERN PERU
}

\author{
Markus Reindel* y Johny Isla**
}

\begin{abstract}
El proyecto "Transecta Andina" del Instituto Arqueológico Alemán investiga las poblaciones prehispánicas que se asentaron entre las regiones de Palpa, en la costa, y Lucanas, en la sierra del sur del Perú. Se han registrado más de 1500 sitios que abarcan el lapso de tiempo desde el período Arcaico Temprano hasta el período Inca (8000 a.C.-1532 d.C.). En cooperación con el Instituto de Geografía de la Universidad de Heidelberg se han reconstruido los cambios paleoclimáticos que se produjeron durante el Holoceno. Los análisis de sedimentos fluviales y eólicos de la costa desértica, así como los estudios paleobotánicos y de pólenes de núcleos extraidos de bofedales de la sierra muestran que el clima experimentó importantes cambios graduales que influyeron en las condiciones de vida y los patrones de asentamiento de las sociedades humanas.
\end{abstract}

Palabras claves: patrones de asentamiento, paleoclima, Andes del sur.

The "Andean Transect" project of the German Archaeological Institutes explores the settlement patterns of the the pre-hispanic populations that occupied a region in southern Peru between the provinces of Palpa on the coast and Lucanas in the highlands. More than 1500 archaeological sites, dating from the Early Archaic period to the Inka period, have been recorded in surveys and excavations. In cooperation with the Institute of Geography of the University of Heidelberg, palaeoclimatic changes that ocurred during the Holocene were recorded in detail. Analyses of fluvial and eolic sediments of the desert coast, as well as analyses of macroremains and polen of drill cores from peat bogs of the highlands demonstrate that climatic parameters changed gradually over time and influenced the living conditions and settlement patterns of the pre-hispanic societies.

Key words: settlement patterns, palaeoclimate, South Andes.

\section{Introducción}

En tiempos prehispánicos los habitantes de los Andes se adaptaron a las condiciones específicas de la gran variedad de regiones ecológicas y desarrollaron actividades y sistemas económicos específicos para cada ambiente natural. Estos sistemas económicos se reflejan en los restos de los asentamientos prehispánicos de cada región, que hoy se pueden detectar con métodos arqueológicos. De acuerdo a la gran variedad ecológica de los Andes, los arqueólogos se ven confrontados con el reto de reconstruir una gran variedad de patrones culturales en un mosáico de hábitats.

La reconstrucción de las condiciones de vida en tiempos prehispánicos se complica todavía más por el hecho de que las condiciones climáticas no fueron estables, sino experimentaron importantes variaciones a través de los siglos. Los cambios de las temperaturas y de las condiciones de humedad resultaron en una variación de los límites entre las zonas ecológicas y, por ende, en un cambio en las bases económicas de las sociedades humanas que vivían en esas zonas. Esto a su vez necesariamente tenía como consecuencia el desplazamiento de los asentamientos y la modificación de los patrones de asentamiento. Para reconstruir estos complejos sistemas de asentamiento, así como el cambio de los patrones de asentamiento en el tiempo, la arqueología tiene que identificar el espacio habitado por el hombre prehispánico a través de la reconstrucción de los restos materiales, que en este caso son los asentamientos.

El movimiento constante de personas y del intercambio de productos entre diferentes pisos ecológicos y zonas de diferentes recursos se ha

\footnotetext{
* Instituto Arqueológico Alemán (DAI), Comisión para Arqueología de Culturas Extraeuropeas (KAAK), Bonn, Alemania. Correo electrónico: markus.reindel@ dainst.de

** ANDES: Centro de Investigación para la Arqueología y el Desarrollo, Lima, Perú. Correo electrónico: isla.nasca@ gmail. com.pe
} 
considerado como una tradición andina milenaria. Con la ayuda de fuentes etnohistóricas de la época colonial se desarrollaron modelos que describen este "control vertical de un máximo de pisos ecológicos" (Murra 1975). En muchas ocasiones científicos han reclamado la necesidad de reconstruir patrones de asentamientos y sistemas económicos de tiempos prehispánicos que reflejen esa verticalidad, también con métodos arqueológicos. Hasta el momento, sin embargo, en ningún proyecto arqueológico se ha investigado la dinámica poblacional y económica en una macrorregión que haya comprendido toda la variedad ecológica de los Andes.

Este objetivo de estudiar el desarrollo cultural y los sistemas económicos de las poblaciones prehispánicas dentro de la variedad ecológica de los Andes, es propuesto por el proyecto "Transecta Andina", que desde 2002 hasta 2011 fue financiado por el Ministerio Federal de Educación e Investigación de Alemania. En cooperación con geógrafos de las universidades Heidelberg y Colonia, especialistas para paleogenética de la universidad de Gotinga y geólogos especializados en el análisis de isótopos de la Colección para Geología y Paleontología del Estado de Baviera en Munich (Bayerischen Staatssammlung für Geologie und Paläontologie in München), y los arqueólogos especializados en Sudamérica del Instituto Arqueológico Alemán estudiaron los patrones de asentamiento en la vertiente occidental de los Andes del sur del Perú.

\section{El área de estudio}

Como área de estudio para el proyecto Transecta Andina se escogió la región de Palpa, en el sur del Perú (Figura 1). En Palpa se encuentra una situación típica para el área andina, caracterizada por una serie de zonas ecológicas muy variadas a una distancia relativamente corta, que permite comunicarse e intercambiar productos entre diferentes pisos ecológicos en poco tiempo. El área de estudio comprende los tributarios septentrionales del río Grande, que tienen su origen en la vertiente occidental de los Andes, a una altura de $4500 \mathrm{~m}$, atraviesan diferentes pisos ecológicos, los oasis fluviales en los pies de los Andes y la amplia faja del desierto costero, para desembocar finalmente en el océano Pacífico.

El desierto de la costa del Pacífico de Sudamérica, que en términos geográficos se conoce como "desierto de Atacama", se extiende desde el Norte de Chile, a lo largo de la costa peruana, hasta la frontera de Ecuador. Con una precipitación media de $5 \mathrm{~mm}$ el desierto de Atacama es uno de los más áridos del mundo. La causa principal de la aridez a lo largo de la costa es la marcada célula de alta presión atmosférica sobre el Pacífico sur y la constancia de los vientos que soplan en sentido de sur a norte de forma paralela a la costa. Aires descendientes y la circulación marítima ascendente, la llamada corriente de Humboldt frente a la costa, producen una estratificación muy estable de las capas atmosféricas, con aire frío abajo y aire cálido arriba. Esta inversión atmosférica produce mucha neblina. La estratificación estable de las masas de aire, sin embargo, impide la convección de aire húmedo y por lo tanto la caida de lluvias.

Las aguas frías de la corriente de Humboldt, ricas en alimentos para la fauna marítima, son la causa de la abundancia de pescados y moluscos en la costa del Perú. A primera vista extraña que justamente esa región inhóspita y árida haya sido el escenario de las primeras sociedades complejas en el Nuevo Mundo, es decir, una de las regiones donde se produjo la transición de una economía de caza, pesca y recolección hacia una economía productiva con estructuras sociales complejas, arquitectura monumental e impresionantes expresiones de arte. En este sentido, Perú se puede considerar como una región modelo en la cual muchas cuestiones básicas del desarrollo de sociedades en el Nuevo Mundo se pueden estudiar y comparar con los desarrollos del Viejo Mundo.

Uno de los objetivos principales del proyecto Transecta Andina fue el estudio de patrones regionales de asentamiento con métodos arqueológicos. Además se ha estudiado con métodos de las ciencias naturales el desarrollo del ambiente natural, especialmente del clima y del paisaje. Finalmente se han analizado las relaciones entre los cambios naturales y los cambios culturales. Partiendo de la hipótesis que cambios del paleoambiente tenían un efecto significativo en el desarrollo cultural, el área de estudio de los Andes tropicales presenta condiciones ideales para investigar la relación entre paleoambiente y desarrollo cultural. Las regiones limítrofes de los desiertos en todo el mundo son áreas que reaccionan de manera muy sensitiva frente a cambios paleoclimáticos. El cambio de los límites de los desiertos, por lo tanto, se puede considerar como indicador inequívoco de cambios climáticos (Eitel, 2007). Estos cambios se pueden 


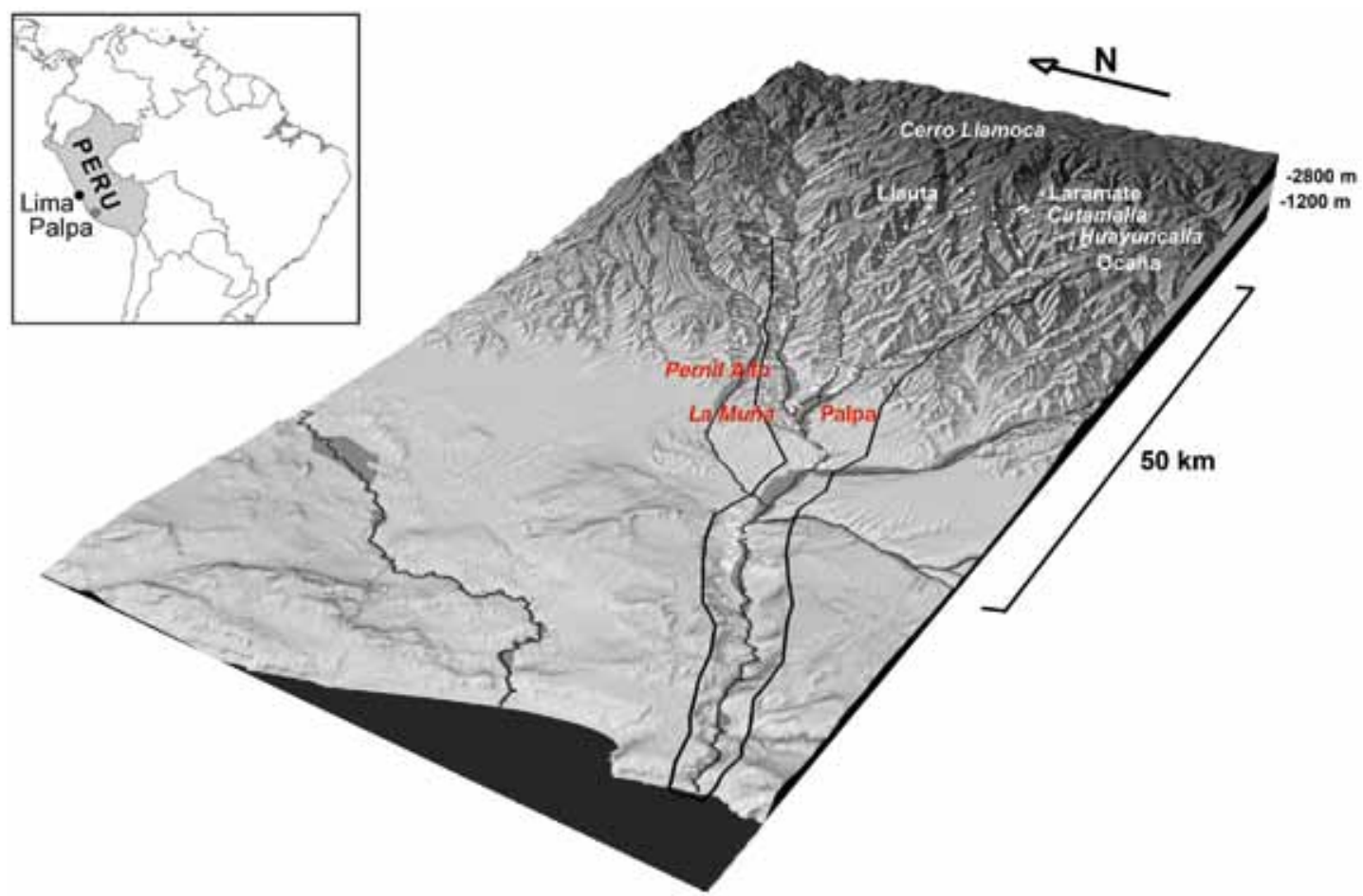

Figura 1. Mapa tridimensional del área de estudio del proyecto Transecta Andina en el sur del Perú, donde se indican importantes sitios arqueológicos y localidades modernas mencionados en el texto. Gráfico: Volker Soßna.

detectar fácilmente con métodos de las geociencias. Al mismo tiempo, la vertiente occidental de los Andes tropicales presenta condiciones ideales para estudios paleoclimáticos, ya que a una distancia de apenas $100 \mathrm{~km}$ se puede observar una secuencia de los hábitats más diversos, que abarcan desde la costa desértica del Pacífico hasta los picos nevados de la cordillera de los Andes (Figura 1).

La región de Palpa se ubica fuera del área de influencia directa del fenómeno de El Niño. Este fenómeno climático radica en cambios de corrientes oceánicas en el Pacífico del sur, que a su vez tienen su origen en la circulación atmosférica global. En intervalos irregulares este fenómeno en el norte del Perú lleva por corto tiempo a condiciones irregulares que resultan en fuertes precipitaciones en la costa y a destrucciones catastróficas. En la costa sur del Perú estos fenómenos de fuertes precipitaciones de origen Pacífico no tienen importancia. Lo que determina el clima en la vertiente occidental son las precipitaciones tropicales de verano. Aires húmedos cruzan la cordillera de los Andes desde la cuenca del Amazonas y llegan hasta el límite del desierto. En el contexto de los cambios climáticos globales de los siglos y milenios pasados, esta corriente monzonal muestra cambios en su intensidad, lo cual produjo en varios instantes cambios del límite del desierto y una variación en el caudal de los ríos de la vertiente occidental de los Andes (Eitel et al., 2005; Mächtle, 2007). En contraste a las catastróficas lluvias del tipo de El Niño en el norte del Perú, de corta duración, pero de rápida recuperación de las sociedades involucradas, los cambios graduales de larga duración que se produjeron en el sur del Perú resultaron en cambios profundos en el comportamiento habitacional. En tiempos de condiciones climáticas desfavorables, asentamientos fueron abandonados, poblaciones enteras emigraron. De manera general, la región se caracterizaba por una vigorosa dinámica poblacional. En Palpa ha sido posible reconstruir estos cambios de los patrones de asentamiento a través de toda la historia prehispánica en el contexto de los cambios del clima y del paisaje.

\section{Estudios de patrones de asentamiento en la costa}

Mientras que las condiciones paleoclimáticas fueron investigadas por los geógrafos de la 


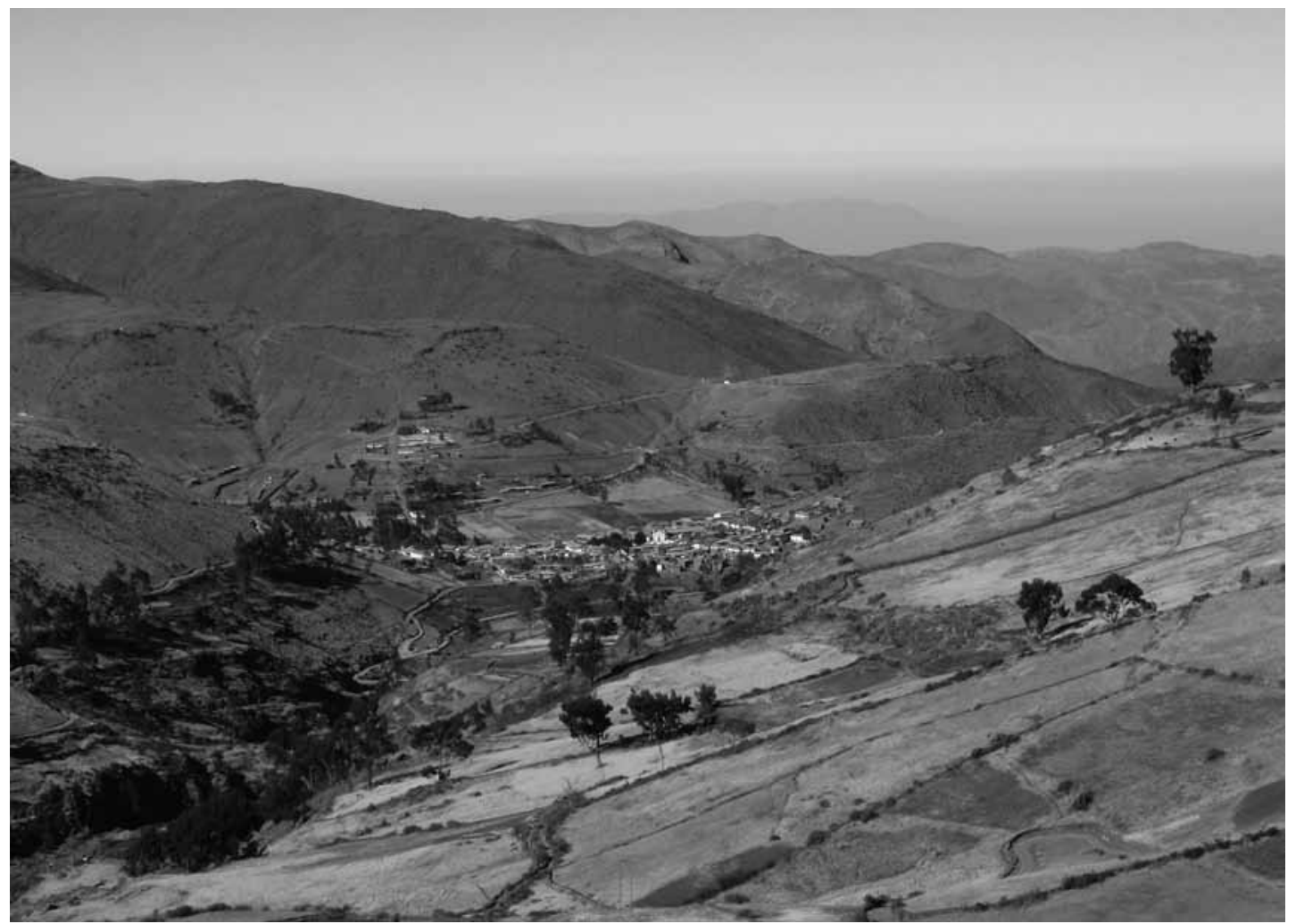

Figura 2. La localidad de Laramate en la sierra de los valles de Palpa, ubicada a una altura de $3200 \mathrm{~m}$, que sirvió de base para los trabajos de campo en la sierra.

universidad de Heidelberg con métodos de las ciencias naturales, los arqueólogos de la Comisión para Arqueología de Culturas Extraeuropeas del Instituto Arqueológico Alemán en cooperación con su colega peruano Johny Isla se dedicaron en una primera etapa del proyecto a la documentación de sitios arqueológicos en la zona de los pies de los Andes, es decir, en la zona de transición entre la costa desértica y la sierra. En esta área de estudio fue posible documentar una secuencia casi ininterrumpida de sitios prehispánicos desde las primeras manifestaciones de vida sedentaria hasta los restos de sitios incaicos del siglo XVI de nuestra era.

El asentamiento más antiguo conocido hasta el momento de la región de Palpa se encontró en el sitio Pernil Alto (Figura 3) (Reindel, 2008, 2010a,b; Reindel/Isla, 2006). Hermann Gorbahn, de la Escuela de Graduados Desarrollo Humano en el Paisaje (Human Development in Landscapes) de la Universidad de Kiel, Alemania, está analizando actualmente los resultados de las excavaciones en el marco de su tesis doctoral. Según los numerosos fechados radiocarbónicos realizados en los laboratorios de Heidelberg y Mannheim, el asentamiento fue habitado en el cuarto milenio a.C., en un período conocido como Arcaico Medio o Tardío (Kaulicke, 1994:242, 2010:391). El sitio está ubicado en la margen derecha del río Grande, en la zona de transición entre el valle medio y el valle bajo. El asentamiento está compuesto por numerosas viviendas circulares u ovaladas ligeramente hundidas en el terreno natural. Originalmente estos pozos estaban cubiertos por una construcción sencilla de ramas, hojas y gramíneas. Probablemente servían para protegerse de la intemperie, mientras que las actividades domésticas se realizaban en las áreas libres entre las chozas. Numerosos batanes y morteros indican que los habitantes de Pernil Alto habían adoptado una vida sedentaria y procesaban plantas que en parte ya estaban domesticadas. Alimentos y otras materias primas procedentes de regiones distantes, como conchas y obsidiana, pero también algunos instrumentos utilizados para la caza, demuestran que los habitantes de Pernil Alto eran muy móviles y que conseguían parte de su alimentación por la caza. Los muertos fueron 


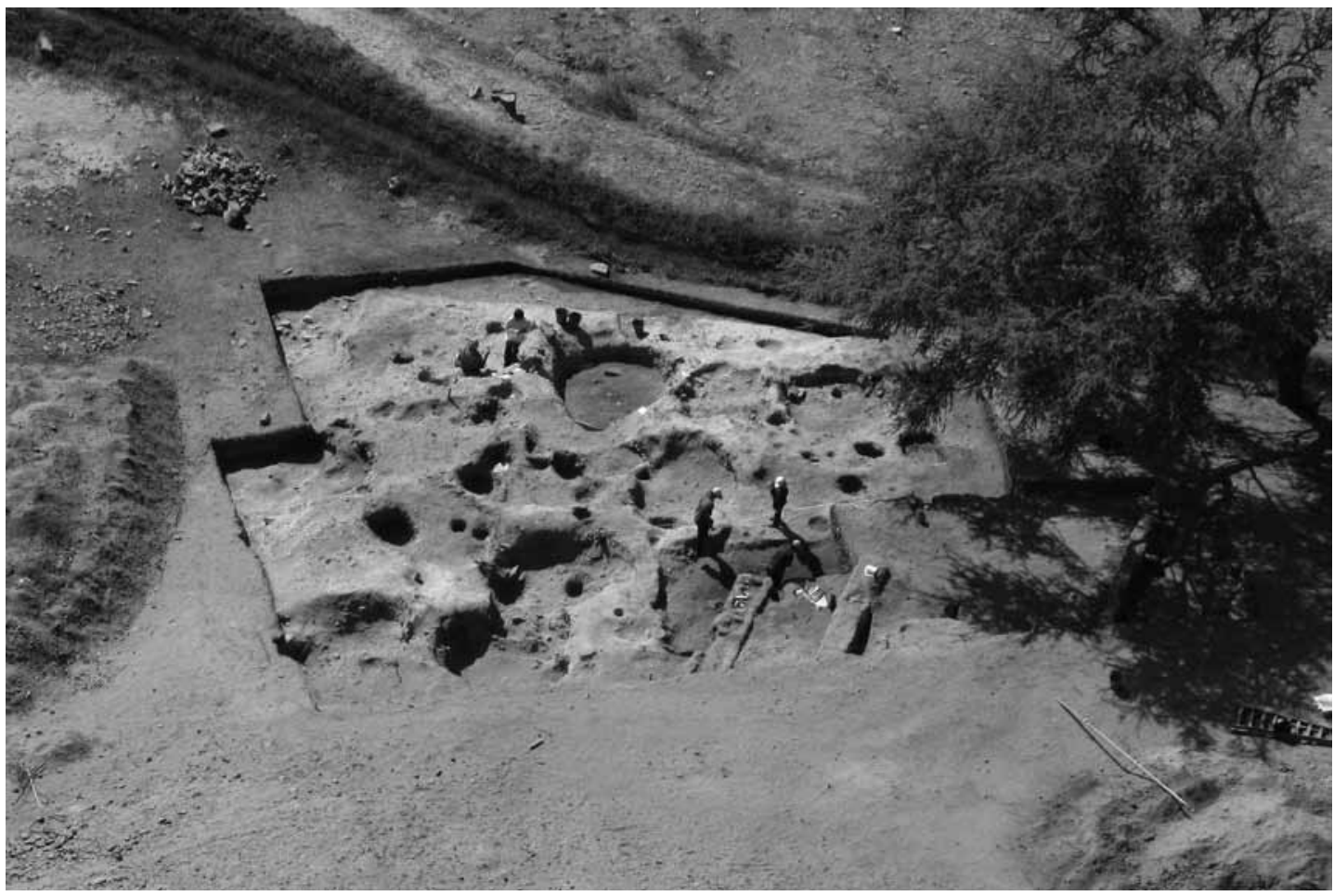

Figura 3. El sitio arcaico de Pernil Alto (3800-3000 a.C.), en la margen derecha del valle de río Grande, donde se encontraron viviendas con pozos circulares y numerosos entierros.

sepultados debajo de los pisos de las viviendas, probablemente después del abandono de estas.

En el mismo sitio de Pernil Alto ha sido posible además excavar en área un asentamiento del período Inicial (1500-800 a.C.)(Reindel/Isla, 2009). El período Inicial está definido por el uso más temprano de la cerámica en el área andina. La cerámica del período Inicial encontrada en Pernil Alto es el antecedente directo de la cerámica de la cultura Paracas (800-200 a.C.). Esta cerámica Paracas igualmente fue documentada en Pernil Alto en un contexto estratigráfico y directamente encima de la cerámica del período Inicial. Es uno de los pocos casos en el cual se pudo documentar cerámica de la fase Temprana de la cultura Paracas en un contexto estratigráfico.

En el curso de las diferentes fases de la cultura Paracas, entre 800 y 200 antes de Cristo, se produjo la ocupación masiva de los oasis de los valles de Palpa (Figura 1). La fase Tardía de la cultura Paracas ya muestra una ocupación bastante densa que se caracteriza por concentraciones llamativas en aquellos lugares que permitieron el acceso fácil a fuentes de agua, es decir, cerca de las salidas de los valles y en la confluencia de los ríos Grande, Palpa y Viscas, que forman una planicie extensa con gran potencial agrícola.

El desarrollo de la ocupación continúa en la primera fase de la época Nasca, el período Nasca Inicial (200 a.C.-100 d.C.). En este período observamos la mayor densidad de asentamientos, pero ningún centro poblacional que destaque de los demás. Evidentemente los recursos naturales permitieron el extenso uso agrícola de la zona, sin que se haya formado una organización central.

Esta situación cambió marcadamente en el período Nasca Temprano (100-300 d.C.), que puede ser considerado como período de florecimiento de la región. Los asentamientos circundan en esa época los bordes de los valles, casi sin dejar áreas libres. Especialmente atractiva debió ser la gran planicie formada for la confluencia de los tres ríos de la región. En el período Nasca Temprano alrededor de esa planicie se formaron centros poblacionales importantes (Reindel/Isla, 2001). Estudios geomorfológicos indican que en esa época se practicaba un intenso cultivo por riego (Hesse, 2008). Sistemas de irrigación requieren organización, la cual a su vez 
da origen a instalaciones centralizadas. Siguiendo esta argumentación, los centros poblacionales del período Nasca Temprano se pueden considerar como centros administrativos que se diferenciaban marcadamente de los caseríos y pueblos agrícolas por su arquitectura planificada.

Parece que con el inicio del período Nasca Medio (300-450 d.C.) las condiciones de vida en los valles de Palpa empeoraron. Numerosos asentamientos de la gran planicie fueron abandonados. Grandes centros poblacionales crecieron con preferencia en las partes medias de los valles, más hacia el este. Importantes cambios se registraron también en la ubicación y la forma de los geoglifos. Estos grandes dibujos en el desierto en su primera manifestación de la época Paracas se habían colocado en las faldas de los cerros. En la época Nasca, sin embargo, se construyeron en dimensiones gigantescas en las pampas del desierto que se encuentran entre los valles de Palpa. A partir del período Nasca Medio se intensificaron las actividades rituales sobre los geoglifos. Los hallazgos arqueológicos sobre los geoglifos demuestran que se practicaron actividades rituales en relación con cultos al agua y a la fertilidad (Lambers, 2006; Reindel et al., 2006).
Claros indicios de simbología relacionada con agua son las ofrendas que se depositaron sobre los geoglifos especialmente en el período Nasca Tardío (450-600 d.C.). En ese período aumentó la construcción de pequeñas plataformas sobre los geoglifos que se pueden considerar como altares o templos que sirvieron como centros de culto (Figura 4) (Reindel et al., 2006). Sobre las plataformas se encontraron restos de vasijas de cerámica, textiles, frutos, fauna marítima y, como ofrenda especial, conchas Spondylus. Las conchas Spondylus se conocen desde las épocas culturales más tempranas del área andina como símbolos de agua y fertilidad (Marcos, 1986; Museo Arqueológico Rafael Larco; Herrera, 1999). Todos estos elementos indican que el agua en esa época se hizo más escasa. La falta de agua se refleja también en los patrones de asentamiento. Los centros poblacionales se trasladaron cada vez más hacia las partes medias de los valles, hacia las regiones serranas donde obviamente había más disponibilidad de agua.

En el período del Horizonte Medio (6001000 d.C.) la actividad poblacional casi colapsa. Se pudieron identificar solo muy pocos sitios con cerámica diagnóstica de ese período. Se

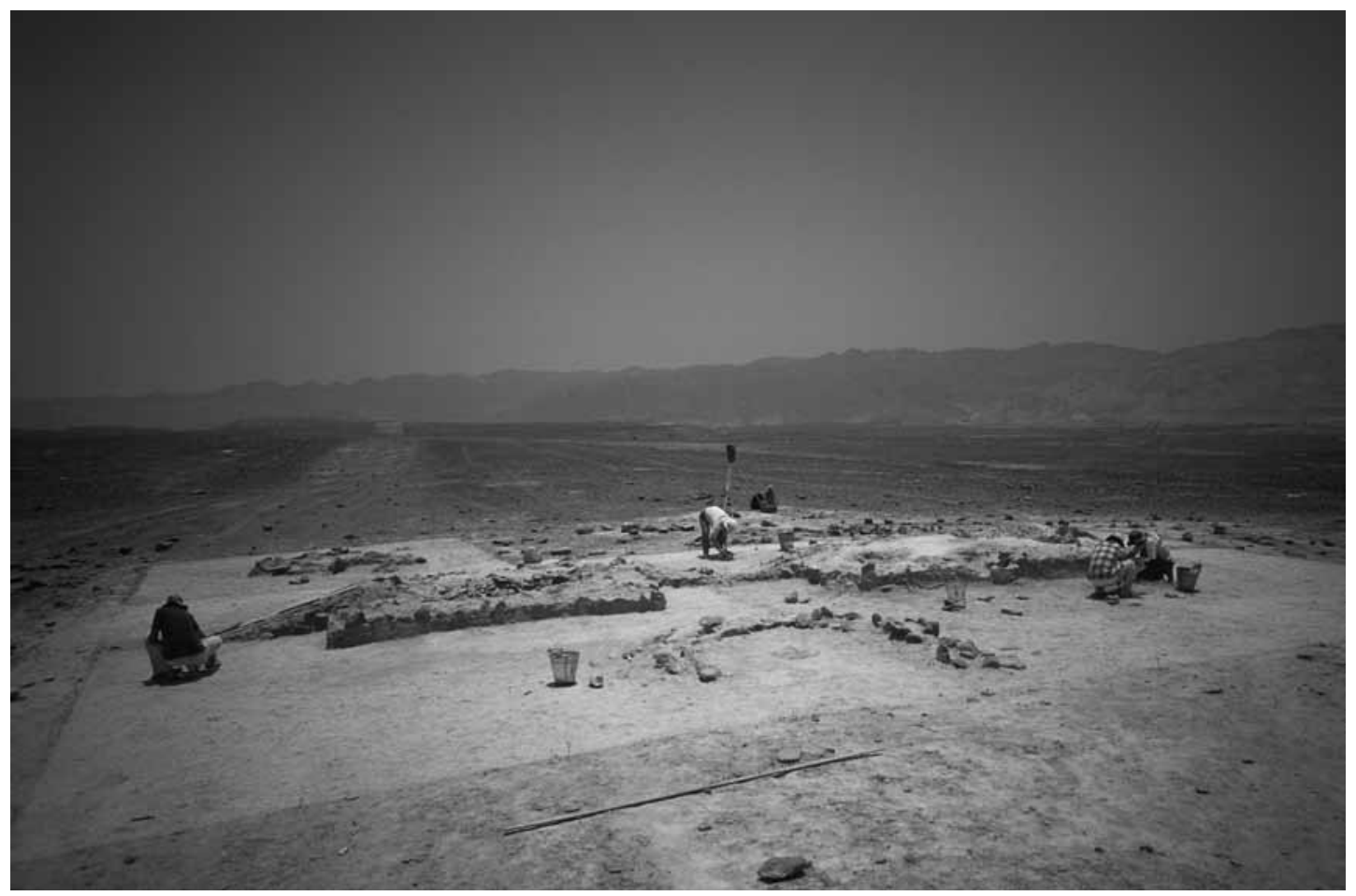

Figura 4. Excavación de plataformas de piedras sobre geoglifos de la época Nasca (200 a.C.-600 d.C.), que sirvieron como lugares para ofrendas en el contexto de cultos al agua y a la fertilidad. 
identificaron algunas tumbas aisladas donde los Huari enterraron sus muertos, pero muy pocos restos de asentamientos. Estas evidencias suscitan preguntas fundamentales sobre el carácter de la ocupación en los valles de Palpa en la época del Horizonte Medio. ¿Será posible que la gente del Horizonte Medio utilizó los valles de Palpa solamente como ruta de tránsito y ya no como lugar para vivir? ¿Habían empeorado tanto las condiciones de vida que la agricultura ya no sirvió como fundamento estable para la supervivencia?

La situación cambió nuevamente de manera radical en el período Intermedio Tardío (1000-1400 d.C.). En esta época volvieron a crecer grandes asentamientos de tipo casi urbano, en algunos casos ubicados a grandes distancias de los fondos de los valles de los ríos, en medio del desierto (Lambers et al., 2007; Reindel et al., 2010). Parece que el agua volvió a estar disponible en abundancia. Esto por lo menos indican las numerosas instalaciones para el control del flujo de agua en las quebradas secas. En el vecino valle de Santa Cruz, Bertil Mächtle, de la Universidad de Heidelberg, identificó instalaciones para el manejo del agua, que en otras partes del mundo se conocen como Tussurs (Africa), Karez (Asia Central) o Khadin (India/Pakistan) (Mächtle, 2009). Por analogía con estos sistemas se puede calcular un promedio de la precipitación anual de aproximadamente 150 a $200 \mathrm{~mm}$ en la época del período Intermedio Tardío, es decir, una cantidad que permitía una modesta agricultura de secano, almacenamiento de agua e incluso el crecimiento de asentamientos a grandes distancias de los oasis fluviales.

\section{Estudios paleoclimatológicos en la costa}

Luego de haber detectado en los estudios arqueológicos varios indicios de cambios paleoclimáticos, se planteó la pregunta si estos indicios se podían identificar también con los métodos de la geomorfología y de las ciencias naturales en general. A la solución de esta pregunta se dedicó el grupo de geógrafos de la Universidad de Heidelberg dirigido por Bernhard Eitel. El punto de partida de las investigaciones fue el descubrimiento de extensos yacimientos de Löss en las faldas de los cerros en la región de Palpa (Eitel et al., 2005). Löss es un sedimento eólico my fino que se deposita sobre la superficie de la tierra solamente bajo la condición de que existe una cobertura de vegetación que pueda fijar el sedimento eólico. Si no existe esta vegetación, el sedimento fino que se origina en los lechos de los ríos en la época de sequía es erosionado rápidamente por el viento. De esta manera, la presencia de Löss fue una prueba indirecta, pero inequívoca, de condiciones climáticas y vegetacionales diferentes en el pasado. Había que concluir, por consiguiente, que en los valles de Palpa en ciertas épocas del pasado reinaba un ambiente más húmedo.

Aplicando la metodología de la Luminiscencia Ópticamente Estimulada (OSL), Annette Kadereit, del Laboratorio de Luminescencia de la Universidad de Heidelberg, demostró que la formación del Löss comenzó hacia 12000 años, es decir, con el inicio del Holoceno. Como muy tarde hacia 2000 a.C. terminó la deposición de sedimentos eólicos. Esto significa que la vegetación que antes fijaba y protegía el sedimento desaparecía paulatinamente, lo cual se puede interpretar como un aumento de aridez. Aún no se puede explicar hasta qué medida la creciente aridez contribuyó a una concentración de los hombres a lo largo de los oasis fluviales y aceleró de esta manera el proceso de cultivo de plantas y el proceso de sedentarización en el período Arcaico. En todo caso los resultados de numerosos otros estudios geomorfológicos y sedimentológicos que se realizaron en el curso de los últimos años confirmaron el proceso de aridización que culminó con una sequía extrema alrededor de 600 d.C. Resulta problemático determinar las causas exactas de ese proceso. Pero el geógrafo Bertil Mächtle ha avanzado interesantes hipótesis para explicar esta aridización en el contexto de la circulación global de la atmósfera (Mächtle/Eitel, 2013). En todo caso la extensa fase de aridez extrema condicionó la extensión del desierto hacia el este, hasta alturas medias de los Andes, y coincide significativamente con el ocaso de la cultura Nasca alrededor de 600 d.C.

\section{Estudio de patrones de asentamiento en la sierra}

¿Adónde había emigrado la gente que anteriormente había vivido en los oasis fluviales fértiles de la región costera? ¿De dónde venía la gente que volvió a reocupar los terrenos en los pies de los Andes, después de haber mejorado las condiciones para la agricultura, con un clima considerablemente más húmedo? En las reconstrucciones de los patrones de asentamiento en la historia prehispánica se había registrado repetidamente un movimiento desde oeste 
hacia el este, desde la costa árida hacia la sierra. $\mathrm{La}$ sierra al este de Palpa, sin embargo, desde el punto de vista arqueológico, era terra incógnita (Figura 2). La falta de estudios en la vertiente occidental de los Andes es una constante en la arqueología del Perú. No había conocimientos sobre asentamientos en las cabeceras de los valles de Palpa que alcanzan alturas hasta $4500 \mathrm{~m}$.

Primeras prospecciones arqueológicas realizadas por Carolina Hohmann en las cabeceras de los valles de Palpa resultaron en el descubrimiento de un número inesperado de asentamientos prehispánicos de todos los períodos (Reindel, 2010a, 2012). Además llamó la atención la gran cantidad de terrazas agrícolas que rodeaban muchos de los asentamientos. Existen regiones donde las faldas de los cerros están completamente cubiertas por andenería, de manera que se formaba un extenso paisaje cultural (Figura 5). Hoy, la densidad poblacional de la zona es baja. La ganadería de vacunos forma la base económica de la gente que vive de manera dispersa en pequeños caseríos y poblados, así como en las tres localidades de Llauta, Laramate y Ocaña (Figura 1). Solo una fracción mínima de los antiguos terrenos de cultivo se sigue utilizando para la agricultura.

Considerando los cambios marcados registrados en el paleoclima de la costa, se puede sospechar que en la sierra también pueden haber regido en el pasado condiciones climáticas que permitían una economía muy productiva. Innumerables corrales antiguos en alturas por encima de los $3800 \mathrm{~m}$ muestran que en tiempos prehispánicos la cría y el manejo de camélidos era de gran importancia. Los camélidos en tiempos prehispánicos eran muy apreciados por su carne y su lana. Además eran los únicos animales de carga en la América prehispánica.

Con las caravanas de camélidos se realizaba el intercambio comercial de productos entre la sierra y la costa. En el área de estudio del proyecto Transecta Andina se descubrieron caminos de larga distancia, marcados por sitios con petroglifos (Fux, 2012). Estos caminos conectaron también los importantes yacimientos de obsidiana de la sierra con la región

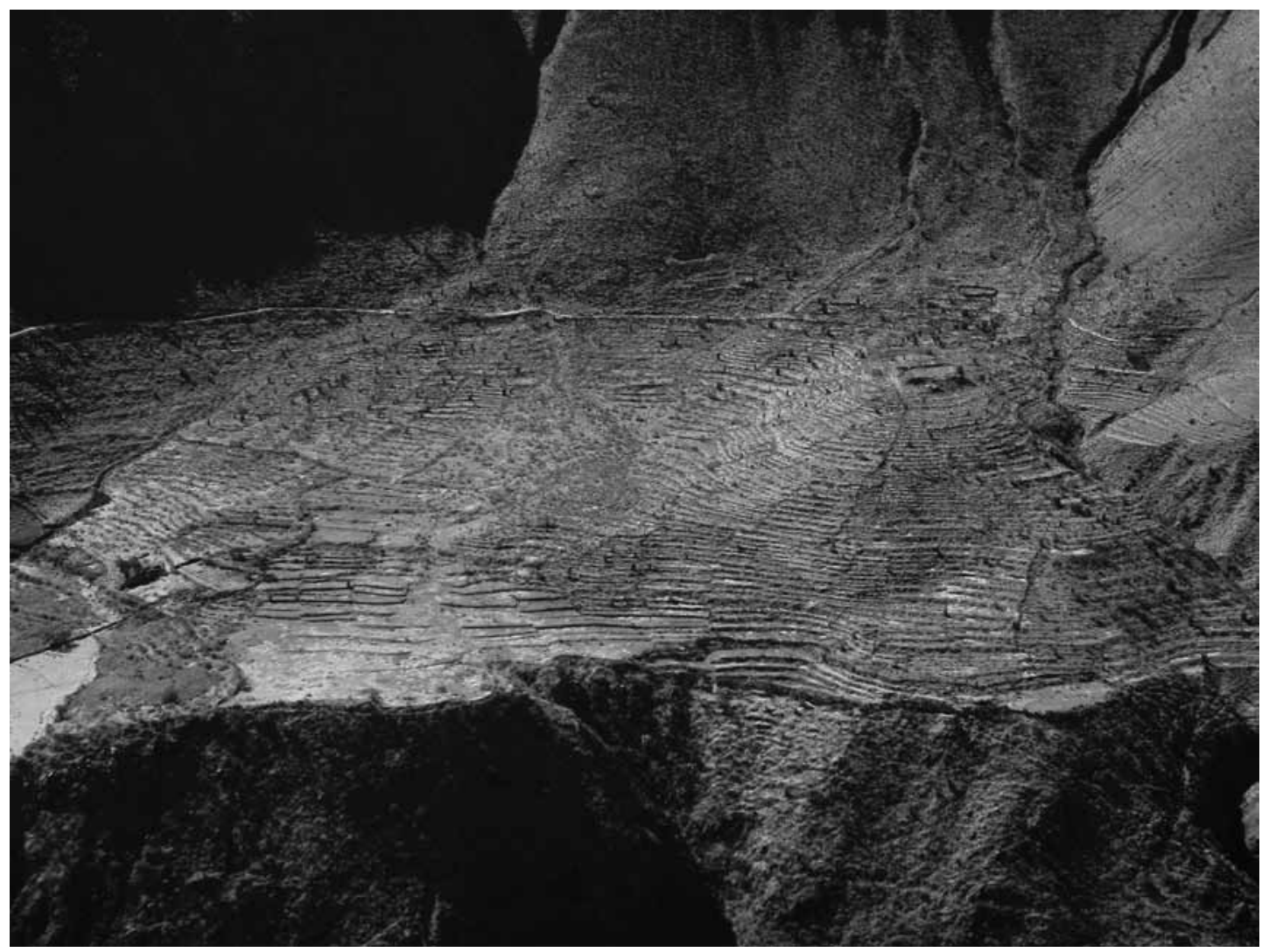

Figura 5. Santa María, un sitio típico del Horizonte Medio y Período Intermedio Tardío (600-1400 d.C.) en las cabezadas de los valles de Palpa, con extensos sistemas de andenerías. 
de la costa (Burger/Glascock, 2000; Tripcevich/ Contreras, 2011). Las fuentes etnohistóricas nos informan que desde la costa en cambio se transportaron algodón, ají y otros productos agrícolas hacia la sierra (Guillén Guillén o.j.). La obsidiana, que era una importante materia prima para la producción de cuchillos, puntas de proyectiles y otras herramientas cortantes, se encuentra solamente en relación con las formaciones volcánicas de la sierra alta de los Andes. Desde los primeros períodos de ocupación del área andina la obsidiana formaba un importante producto de intercambio. Se encuentra ya en los contextos arcaicos del cuarto milenio antes de Cristo en el sitio Pernil Alto. En la sierra se documentaron artefactos de obsidiana en las excavaciones del Abrigo Llamoca, que arrojaron fechados radiocarbónicos de 8000 años antes de Cristo (Reindel, 2012). En los alrededores del sitio se encontraron artefactos y contextos arqueológicos que atestiguan una ocupación muy temprana por cazadores y recolectores. Instrumentos unifaciales hechas de rocas cristalinas se pueden interpretar incluso como evidencia del hombre de las primeras fases de ocupación de Sudamérica, que se conoce como período Paleoindiano (11000-8000 a.C.).

\section{Estudios paleoclimatológicos en la sierra}

No sorprende la presencia del hombre temprano en el área del cerro Llamoca, a una altura de más de $4000 \mathrm{~m}$ (Figura 1). En esa zona ecológica los cazadores encontraron muchos animales silvestres, así como las piedras volcánicas que necesitaban como materia prima para sus instrumentos cortantes. El paisaje alrededor del cerro Lamoca está caracterizado por un extenso bofedal que está alimentado por varios manantiales que brotan al pie de unos macizos rocosos (Figura 6). Los manantiales produjeron el agua necesaria para los asentamientos humanos, los animales encontraron en el bofedal su alimento fresco incluso en la época de sequía.

Además el bofedal tiene crucial importancia como geoarchivo. Por la constante humedad a través de los milenios se ha formado una cobertura de plantas que se ha conservado en tal estado, que los restos botánicos de miles de años de antigüiedad se pueden identificar todavía hoy macroscópicamente y se pueden extraer pólenes para el análisis arqueobotánico. Las plantas son importantes indicadores de los climas específicos de diferentes períodos del pasado. Mediante análisis de plantas y pólenes del bofedal de Llamoca se pudieron hacer por lo tanto inferencias sobre el clima en el pasado. De esta manera en el marco del proyecto Transecta Andina se ha formado un archivo climatológico único que en partes tiene una resolución temporal de hasta diez años. Markus Forbriger, del grupo de los geógrafos de la Universidad de Heidelberg, está investigando ese geoarchivo excepcional en cooperación con Karsten Schittek, del Instituto de Geografía de la Universidad de Colonia.

Por el fechado de más de cien muestras de restos orgánicos extraidos mediante perforaciones profundas en el bofedal, Bernd Kromer, del laboratorio de radiocarbono del Centro Curt Engelhorn de Mannheim, pudo determinar la edad de las capas acumuladas. Las capas más antiguas se habían formado en el sexto milenio antes de Cristo. Con esa cantidad de fechados se puede paralelizar la historia de la formación del paisaje con la cronología arqueológica, lo cual permite hacer inferencias sobre las condiciones de vida de la población prehispánica de la sierra y compararlas con las de la costa.

Los resultados obtenidos del análisis de los archivos climáticos de la sierra concuerdan perfectamente con los resultados obtenidos por el análisis geomorfológico de sedimentos de la costa. En los perfiles de los pólenes se registra una larga fase relativamente húmeda en la primera parte del Holoceno (Reindel/Eitel, 2012; Schittek et al., 2012). La costa en esa época probablemente estaba caracterizada por una vegetación de tipo estepa, que presentaba condiciones ideales para la supervivencia de grupos de cazadores y recolectores. La creciente población, sin embargo, que se alimentaba de la recolección de plantas, de la caza de animales y del aprovechamiento de los ricos recursos marinos, en la segunda mitad del Holoceno se vio forzada a concentrarse en las cuencas de los ríos como consecuencia de un proceso de aridización. Este proceso de concentración pudo haber sido el incentivo para desarrollar nuevas formas de convivencia. Esto a su vez podría haber sido el inicio del desarrollo de sociedades más grandes y complejas en el cuarto milenio antes de Cristo.

En todo el proceso del desarrollo cultural el intercambio de productos y la movilidad de la gente entre la sierra y la costa debió haber jugado un papel importante. Esto demuestran los hallazgos de obsidiana en la costa en todos los períodos investigados, pero también las rutas de comunicación que por lo 


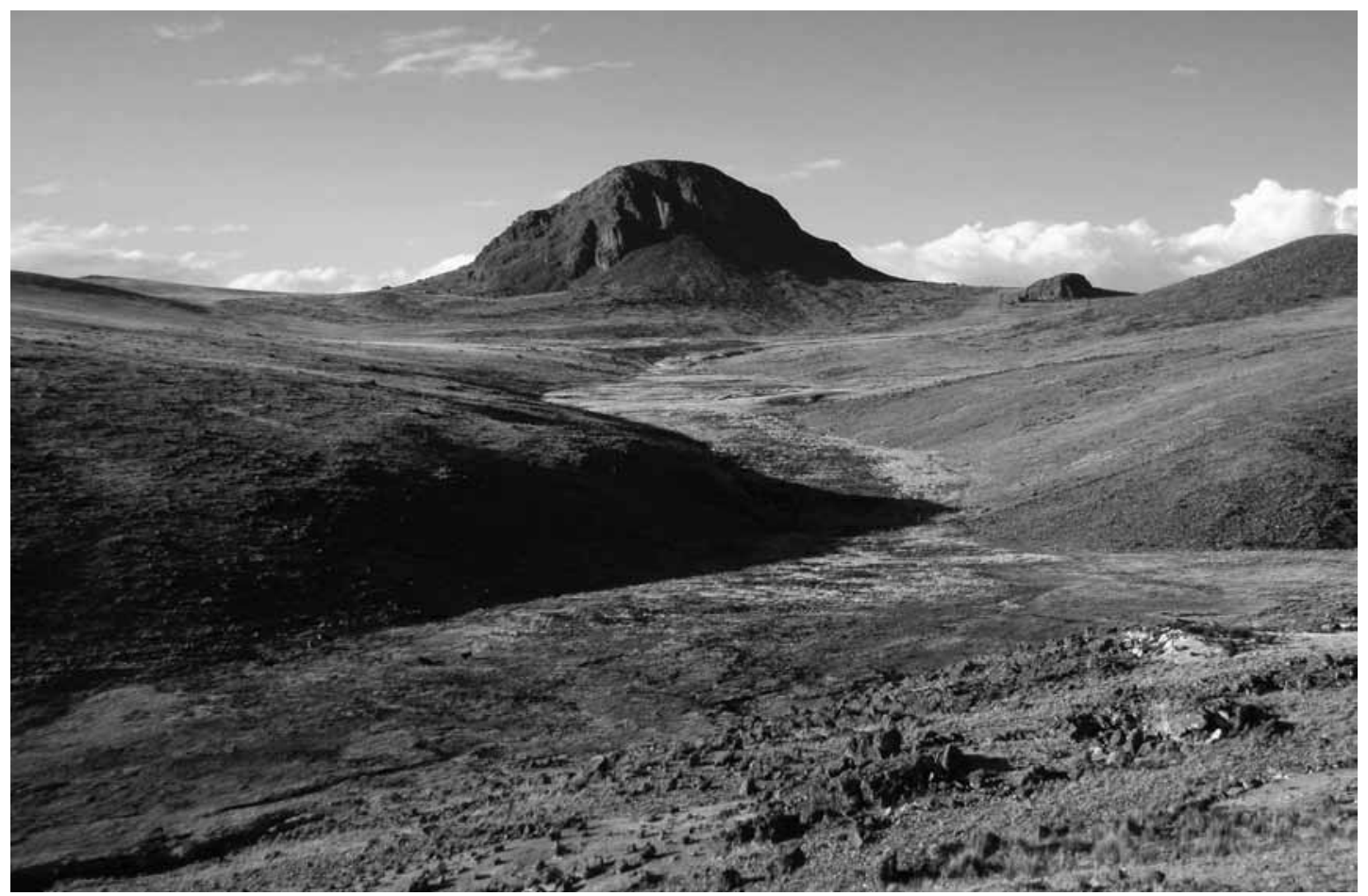

Figura 6. El cerro Llamoca, punto más alto y sitio sagrado en el extremo este de la Transecta Andina. Delante del macizo rocoso se extiende un bofedal que sirvió como geoarchivo para estudios paleoclimáticos.

menos desde la época Paracas tenían un significado importante para el intercambio de productos entre la sierra y la costa. Para investigar este fenómeno con más detalles se efectuaron extensas excavaciones arqueológicas en dos asentamientos de la sierra, en Cutamalla y en Huayuncalla.

\section{Excavaciones recientes en la sierra}

El sitio de Cutamalla, un asentamiento Paracas ocupado entre 600 y 200 a.C., atrajo nuestra atención por su estructura arquitectónica única y nunca vista anteriormente en otros sitios (Figuras 7, 8). Como módulo básico de un complejo arquitectónico se pudo definir una plaza circular hundida de unos 25 $\mathrm{m}$ de diámetro. Esta plaza circular estaba rodeada por estructuras en forma de $\mathrm{D}$, de tal manera que resultaba una forma parecida a los contornos de una flor. En el curso de las excavaciones, dentro de la estructura en D se encontraron unos pozos cilíndricos, en muchos casos revestidos de piedra, que se pueden interpretar como depósitos. Otros pozos más sencillos se encontraron debajo del piso del patio interior. Estos se pueden considerar como versiones más primitivas de depósitos.
Los supuestos depósitos dan un carácter especial al sitio de Cutamalla. El módulo básico, formado por los complejos circulares en forma de flor, se repite en Cutamalla por lo menos diez veces, de manera que la capacidad de almacenamiento era considerable. En el interior de los complejos circulares se encontraron numerosas herramientas que hacen suponer que las estructuras fueron utilizadas para actividades productivas. Todavía no se puede decir con certeza qué tipo de productos se procesaron en Cutamalla. En el futuro esperamos poder definir con más precisión esas actividades a base de los resultados de análisis de las numerosas muestras de suelo que se han tomado del interior y de los alrededores de los depósitos. Probablemente estas actividades estaban relacionadas con el cultivo en las amplias terrazas agrícolas que rodean el sitio, así como con los productos de la ganadería que se practicaba a alturas más grandes. Posiblemente Cutamalla fue el centro de una colonia agraria y de pastoreo de la cultura Paracas. Los centros poblacionales más importantes de la cultura Paracas estaban en la costa, mientras que en la sierra se procesaban ciertos productos (p.e. maíz, lana, etc.) que fueron almacenados temporalmente en 


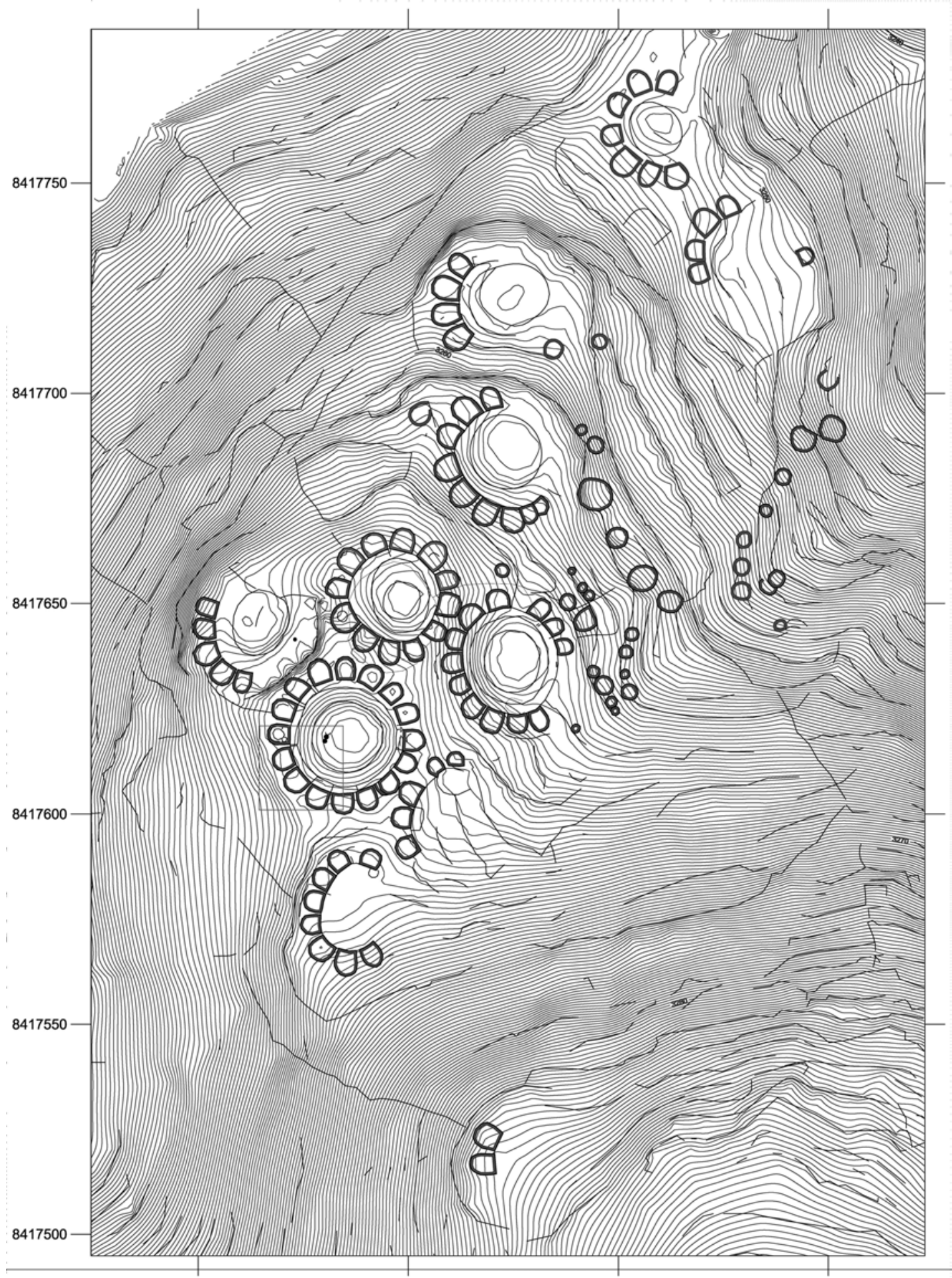

Figura 7. Plano de la parte norte del sitio Cutamalla (Paracas Tardío, 600-800 a.C.) donde se aprecian estructuras en forma de flor, con patios circulares hundidos rodeados por estructuras en forma de D. 


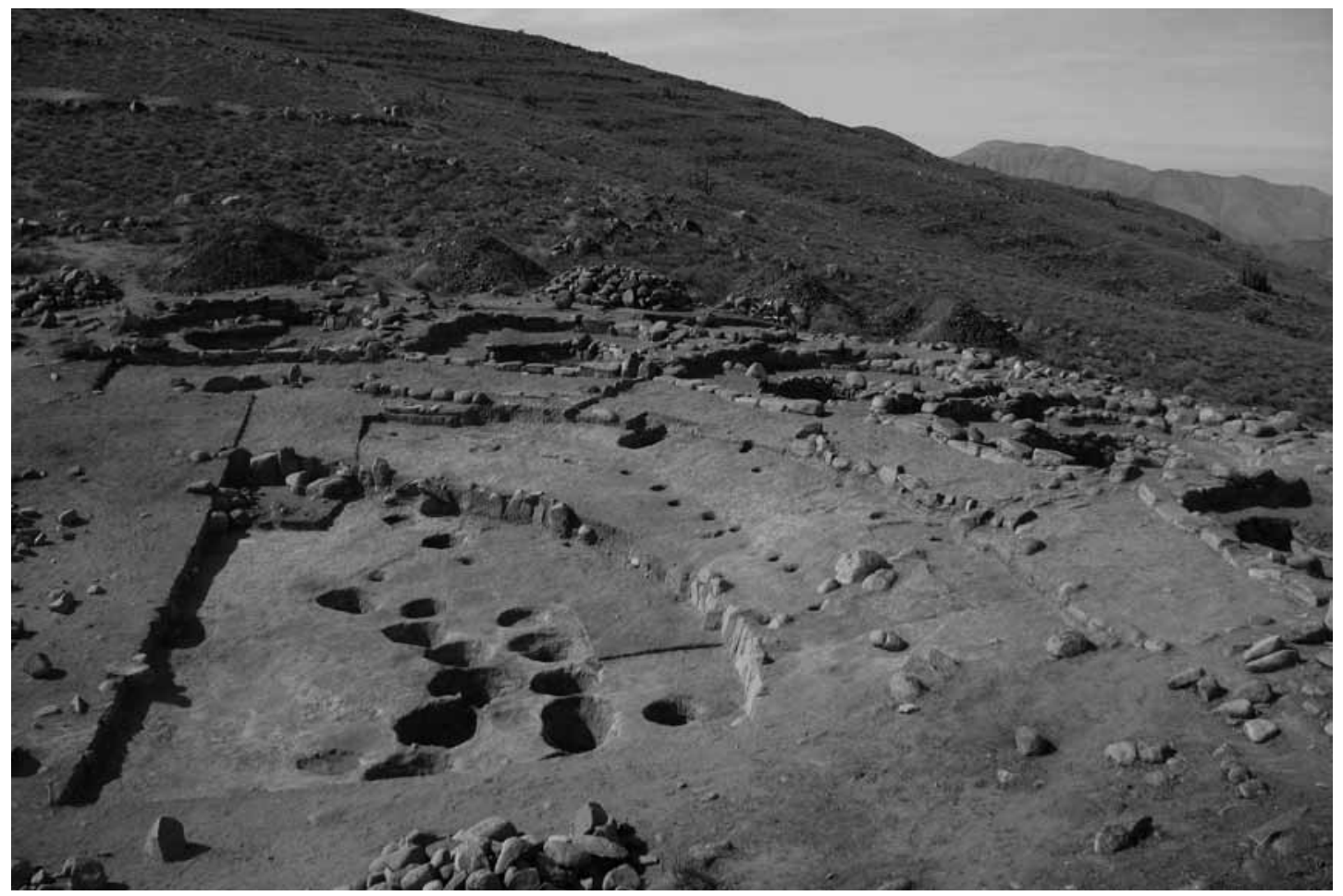

Figura 8. Excavación de una de las estructuras en forma de flor en el sitio de Cutamalla, donde se aprecia el patio hundido con pozos, la terraza y las estructuras en forma de D con cistas.

depósitos y luego transportados con caravanas de llamas a la costa.

El sitio de Huayuncalla fue excavado para obtener evidencias representativas del período Nasca (200 a.C.-600 d.C.) y del Horizonte Medio (600-1000 d.C.). En Huayuncalla también se identificaron los típicos complejos circulares de la época Paracas. Estas, sin embargo, fueron tapados por las ocupaciones posteriores de las culturas Nasca y Huari (Figuras 9, 10). Esta secuencia ocupacional fue ideal para documentar los procesos de cambio de patrones de asentamiento en el área de estudio de la Transecta Andina. Según las reconstrucciones de la historia cultural y del paleoclima realizadas hasta el momento, la ocupación Nasca en la sierra en gran parte es la consecuencia del empeoramiento de las condiciones de vida en la costa árida. Luego de la época Nasca Temprano, cuando las condiciones climáticas en los pies de los Andes eran muy favorables para la agricultura y para la vida en general, con la aridización en el período Nasca Medio y especialmente en el período Nasca Tardío aumentó la densidad poblacional en la sierra. En esa fase probablemente se intensifican también los contactos con los grupos que vivían en el Altiplano, es decir, la zona altoandina entre las cordilleras oeste y este. Estos grupos que posteriormente formaron la famosa cultura Huari del Horizonte Medio, paulatinamente ampliaron su área de ocupación hacia el oeste, ocuparon los antiguos asentamientos Nasca y avanzaron hasta las regiones de la costa. En la costa, sin embargo, en la región de Palpa apenas se han identificado asentamientos de los Huari. Solamente los fragmentos de cerámica y algunas tumbas muy elaboradas atestiguan la presencia de los Huari en los valles de la costa. Evidentemente el interés de los Huari en la costa radicaba en el aprovechamiento de los productos y los recursos de la costa, los cuales se consiguieron por intercambio o comercio, o bien por la explotación directa de yacimientos de materia prima (p.e. cobre) (Reindel et al., 2013).

El asentamiento de Huayuncalla se encuentra sobre una loma a unos $7 \mathrm{~km}$ al suroeste de la localidad de Laramate, a una altura de $3200 \mathrm{~m}$ (Figura 1). Los restos arquitectónicos visibles sobre la superficie se componen por un lado por una gran cantidad de estructuras circulares de $3 \mathrm{~m}$ a $6 \mathrm{~m}$ de diámetro (Figura 9). Por otro lado se observan áreas con muros de piedras dispuestas en un patrón 


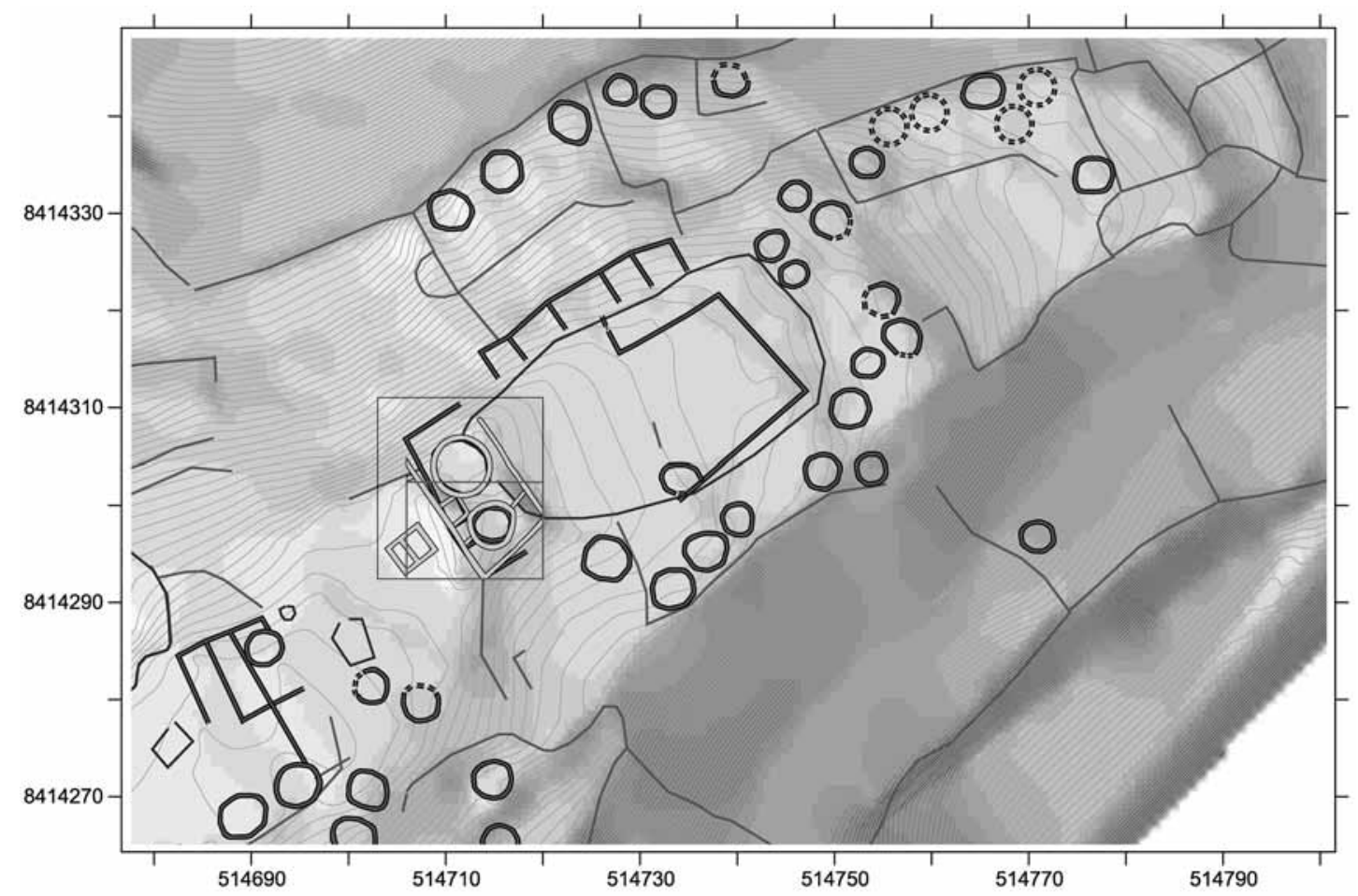

Figura 9. Plano de la parte noreste del sitio Huayuncalla (Paracas Tardío hasta Horizonte Medio, 400 a.C.-1000 d.C.), donde se ven las estructuras en la parte más alta del sitio con un complejo funerario que consistió de dos estructuras circulares enmarcadas por un muro rectangular.

marcadamente ortogonal. En la periferia noroeste del asentamiento se encuentran algunas estructuras funerarias, conocidas como Kuntis.

La aparición de los Huari en el sitio de Huayuncalla se puede identificar claramente por su característico estilo arquitectónico. En contraste a culturas anteriores cuyas construcciones tenían plantas circulares, los Huari preferían para la construcción de sus edificios públicos mayormente un patrón rectangular. En muchas partes de Huayuncalla este tipo de estructuras rectangulares se sobreponen a las estructuras circulares de los Paracas y Nasca (Figura 10).

En la parte más alta del asentamiento de Huayuncalla se identificaron dos complejos funerarios que combinaron estos dos elementos arquitectónicos. Dos estructuras circulares estaban enmarcadas por muros rectangulares. La excavación reveló que dentro de cada uno de los complejos se encontraron cámaras funerarias con los restos de por lo menos 20 individuos sepultados de manera secundaria. Como ofrendas se encontraron vasijas de cerámica (Figura 11) y -como elemento llamativamente nuevo- una gran cantidad de objetos de cobre y oro. Todavía no se pudo determinar si los metales procedían de la rica zona de metales de la costa (Reindel et al., 2013) o de la sierra misma. En todo caso parece que los metales en la época Huari jugaban un papel importante.

\section{Conclusiones}

El análisis de patrones de asentamiento registrados a lo largo de una línea imaginada en la vertiente occidental de los Andes que abarca todas las zonas ecológicas conocidas, desde la costa del Pacífico hasta las cumbres nevadas de la cordillera occidental, nos ha demostrado cómo la regionalización y la dinámica poblacional prehispánica en los Andes puede ser reconstruida con métodos arqueológicos. Importantes cambios culturales coincidieron con cambios significativos del paleoclima. Sin querer caer en el tópico del determinismo natural, vemos en el caso de nuestra área de estudio en los valles de Palpa claramente una causalidad que nos permite entender mejor la dinámica cultural en los Andes 


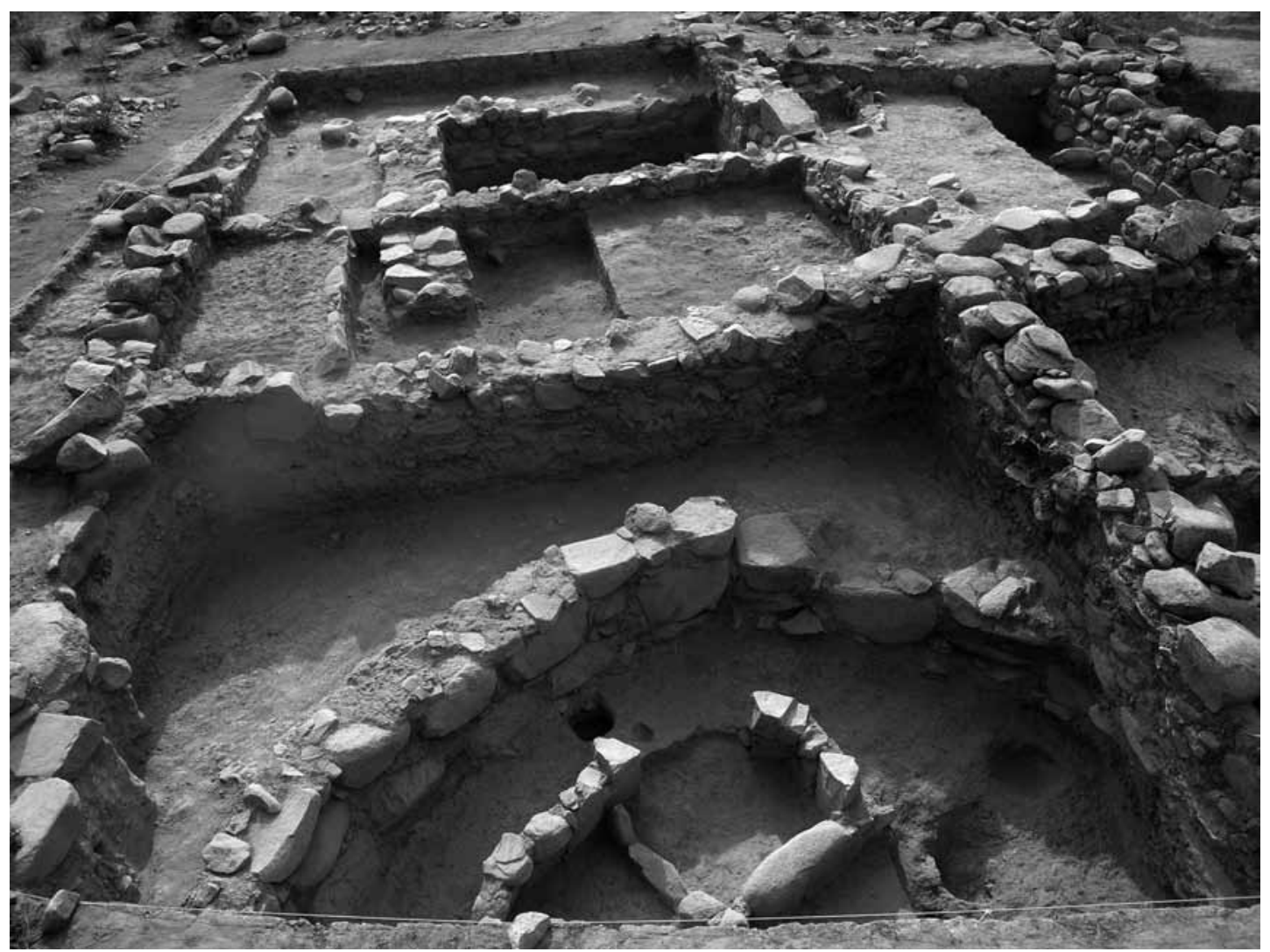

Figura 10. Excavación de estructuras construidas en un patrón rectangular, de la época Huari (600-1000 d.C.), encima de estructuras circulares de las épocas Nasca (200 a.C.-600 d.C.) y Paracas (800-200 a.C.).

prehispánicos en general. Los procesos climáticos en la costa norte del Perú en intervalos irregulares fueron interrumpidos por el fenómeno de El Niño, que trae lluvias torrenciales y destrucciones catastróficas. La costa sur, sin embargo, no fue afectada por esos trastornos. Allí los cambios a largo plazo y su efecto sobre el cambio de patrones de asentamiento se pudieron estudiar de manera ejemplar.

El intercambio de productos sobre largas distancias y el movimiento de gente en la Transecta Andina, pero también el cambio de la ubicación de centros poblacionales y la migración de sectores enteros de la población, se han registrado en todos los períodos de ocupación. La posibilidad de emigrar hacia otras zonas ecológicas, no muy distantes, en situaciones de empeoramiento de las condiciones ambientales, parece haber sido una componente importante del desarrollo cultural en los Andes.

En el transcurso de la historia prehispánica los oasis fluviales en la costa desértica parecen haber sido el hábitat preferido de los pobladores del área andina. Si el clima era más húmedo, la población se concentraba en las cuencas bajas de los ríos, donde se podía practicar la agricultura con sistemas de irrigación. En casi todas las épocas, sin embargo, existían simultáneamente asentamientos de las mismas culturas en las regiones serranas, las cuales se comunicaban por caminos de larga distancia con los sitios de la costa. Las evidencias arqueológicas indican que los asentamientos de la sierra tenían la función principal de proveer los sitios de la costa con productos de la agricultura y de la ganadería (cereales, tubérculos, verduras, carne, lana, etc.). Estos sitios de la sierra cumplieron por lo tanto en primer lugar funciones económicas, mientras que los lugares de asentamiento preferido en el lado occidental de los Andes -tal como ocurre todavía en la actualidad- se ubicaban en la costa. Allí se encontraban también los centros poblacionales más grandes, con la arquitectura más suntuosa (Massey, 1983; Bachir/Llanos, 2012). Solo en la época del Horizonte Medio la vertiente occidental de los 


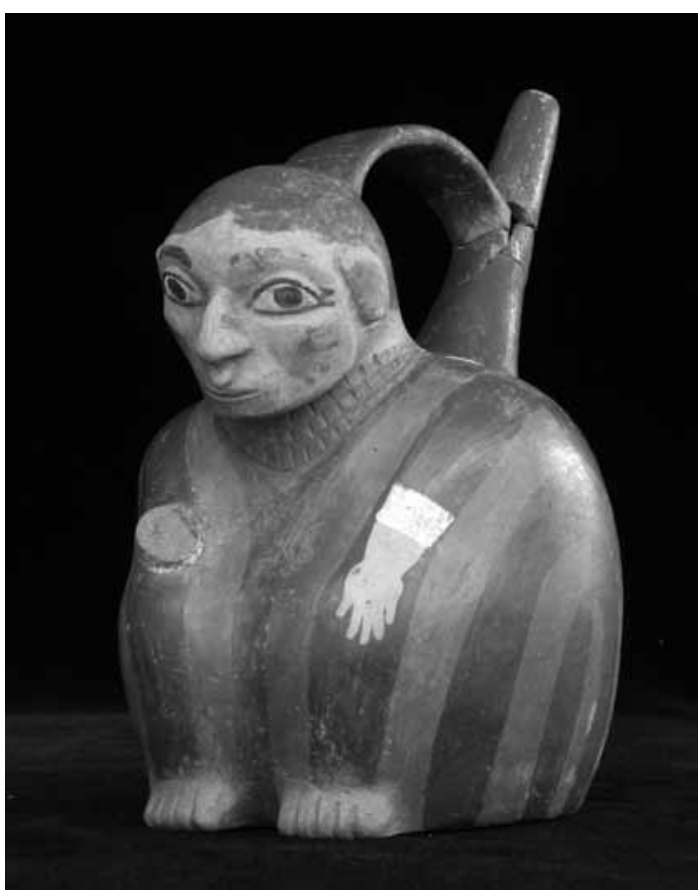

Figura 11. Vasija escultórica Huari (600-800 d.C.) encontrada en el complejo funerario excavado en la parte más alta del asentamiento de Huayuncalla.

Andes, que tradicionalmente se orientaba hacia la costa, fue incluida durante varios siglos en el espacio ocupacional de la sierra por los pobladores serranos de la cultura Huari.

Según los datos paleoclimáticos, la vertiente occidental de los Andes, entre aproximadamente 600 y 1200 d.C., vivía un período de extrema aridez, mientras que las condiciones climáticas en la sierra eran mucho más favorables para la vida humana.
Solo en el período Intermedio Tardío, cuando el clima en toda la extensión del área de investigación del proyecto Transecta Andina adoptó nuevamente condiciones más húmedas, la vertiente occidental de los Andes hasta las tierras bajas de la costa volvió a convertirse en un espacio donde florecieron las actividades habitacionales y económicas.

Las investigaciones del proyecto Transecta Andina han demostrado cómo los cambios climáticos en el curso de la historia prehispánica de los Andes Centrales repetidamente han llevado a cambios en los sistemas socioeconómicos regionales. Estos resultados formarán una base sólida para futuras investigaciones sobre el desarrollo cultural en los Andes. Resultan interesantes, por ejemplo, las preguntas acerca de la importancia de cambios paleoambientales para los cambios en la dinámica poblacional en las épocas arcaicas. ¿Será posible que la concentración de los hombres en épocas secas en los oasis de la costa fue el primer paso para la formación de estructuras sociales más complejas? De igual manera queda por investigar si el fortalecimiento de las culturas de la sierra, apoyado por condiciones climáticas favorables, ha favorecido la formación de grandes redes de intercambio o comercio con caravanas de camélidos y finalmente a la formación de grandes confederaciones e imperios como aquel de los Huari y Tiahuanaco, así como el imperio de los Incas (Golte 2000). En todo caso parece claro que el aprovechamiento de los diferentes pisos ecológicos y espacios económicos, así como la movilidad entre estas regiones en todas las épocas de la historia de los Andes fue la base de exitosos sistemas de desarrollo cultural.

\section{Referencias Citadas}

Bachir Bacha, Aïcha y Llanos Jacinto, Oscar D.

2012 "Arqueología e iconografía de los textiles Paracas descubiertos en Ánimas Altas, Ica, Perú”. In: Solanilla, Victoria (Hg.): Actas de las V Jornadas Internacionales sobre Textiles Precolombinos. Publicaciones del Grup d'Estudis Precolombins 6. Barcelona: Universidad Autónoma de Barcelona, S. 211-230.

Burger, Richard y Glascock, Michael D.

2000 "Locating the Quispisisa obsidian source in the department of Ayacucho, Peru". Latin American Antiquity, 11(3): 258-268.

Eitel, Bernhard

1997 "Kulturentwicklung am Wüstenrand. Aridisierung als Anstoß für frühgeschichtliche Innovation und Migration“. In: Wagner, Günther A. (Hg.): Einführung in die Archäometrie. Heidelberg/Berlin: Springer-Verlag, S. 301-319.
Eitel, Bernhard; Hecht, Stefan; Mächtle, Bertil; Schukraft, Gerd; Kadereit, Anette; Wagner, Günther A.; Kromer, Bernd; Unkel, Ingmar; Reindel, Markus

2005 "Geoarchaeological evidence from desert loess in the Nazca-Palpa region, southern Peru: Palaeoenvironmental changes and their impact on Pre-Columbian cultures". In: Archaeometry, 47, H.1: 137-158.

Fux, Peter

2012 "The Petroglyphs of Chichictara, Palpa, Peru. Documentation and interpretation using terrestrial laser scanning and image-based 3D modeling". In: Zeitschrift für Archäologie Außereuropäischer Kulturen, 4: 127-205.

Golte, Jürgen

2000 "Zur Bedeutung von Fernhandelsbeziehungen in der Geschichte der Anden”. In: Böttcher, Nikolaus/Hausberger, Bernd (Hg.): Geld und Geschäft in der Geschichte 
Lateinamerikas. Bibliotheca Ibero-Americana 77. Frankfurt/M.: Vervuert. S. 19-38.

Guillén Guillén, Edmundo o.j.

s/a Las Parcialidades de Hatun Rukana y Laramati en el Siglo XVI: Represión de la campaña anticristiana de 1569 y descripción de sus pueblos en 1586 (1). URL: http:// www.geocities.ws/edmundoguillenguillen/paginas/documentos/html/las_parcialidades1.html (Datum der Einsicht: 24.1.2013).

Hesse, Ralf

2008 Fluvial Dynamics and Cultural Landscape Evolution in the Rio Grande de Nazca Drainage Basin, Southern Peru. British Archaeological Record International Series, 1787. Oxford: Archaeopress.

Kaulicke, Peter

1994 Historia General del Perú. Tomo I. Los Orígenes de la civilización andina. Lima: Editorial Brasa S.A.

Kaulicke, Peter

2010 Las cronologías del Formativo. 50 años de investigaciones japonesas en perspectiva. Lima: Fondo Editorial de la Pontificia Universidad Católica del Perú.

Lambers, Karsten

2006 The Geoglyphs of Palpa, Peru: Documentation, Analysis and Interpretation. Forschungen zur Archäologie Außereuropäischer Kulturen, 2. Aichwald: Linden Soft.

Lambers, Karsten; Eisenbeiss, Henri; Sauerbier, Martin; Kupferschmidt, Denise; Gaisecker, Thomas; Sotoodeh, Soheil; Hanusch, Thomas

2007 "Combining photogrammetry and laser scanning for the recording and modelling of the late intermediate period site of Pinchango Alto, Palpa, Peru". In: Journal of Archaeological Science 34: 1702-1710.

Mächtle, Bertil

2007 Geomorphologisch-bodenkundliche Untersuchungen zur Rekonstruktion der holozänen Umwelgeschichte in der nördlichen Atacama im Raum Palpa, Südperu. Heidelberger Geographische Arbeiten, 123. Heidelberg: Selbstverlag des Geographischen Instituts der Universiät Heidelberg.

Mächtle, Bertil

2009 Built on Sand: "Climatic Oscillation and Water Harvesting During the Late Intermediate Period”. In: Reindel, Markus/ Wagner, Günther A. (Hg.): New Technologies for Archaeology. Multidisciplinary Investigations in Palpa and Nasca, Peru. Berlin/Heidelberg: Springer-Verlag, S. 39-46.

Mächtle, Bertil; Eitel, Bernhard

2013 "Fragile landscapes, fragile civilizations - How climate determined societies in the pre-Columbian south Peruvian Andes". In: Catena, 103: 62-73.

Marcos, Jorge

1986 "Intercambio a larga distancia en América: el caso del Spondylus”. In: Marcos, Jorge (Hg.): Arqueología de la costa ecuatoriana: nuevos enfoques. Biblioteca Ecuatoriana de Arqueología, 1. Quito: ESPOL Corporación Editora Nacional.

Massey, Sarah A.

1983 “Antiguo centro Paracas-Ánimas Altas”. In: De Lavalle, José Antonio (Hg.): Culturas precolombinas: Paracas. Lima: Banco de Crédito del Perú. S. 134-160.

Murra, John V.

1975 "El control vertical de un máximo de pisos ecológicos en la economía de las sociedades andinas". In: Murra, John
V. (Hg.): Formaciones económicas y políticas del mundo andino. Lima: Instituto de Estudios Peruanos, S. 59-115.

Museo Arqueológico Rafael Larco Herrera (Hg.)

1999 Spondylus. Ofrenda sagrada y símbolo de la paz. Lima: Fundación Telefónica del Perú.

Pulgar Vidal, Javier

1981 Geografía del Perú: las ocho regiones naturales del Perú. Lima: Editorial Universo, S.A..

Reindel, Markus

2008 "Life at the edge of the desert. Archaeological reconstruction of the settlement history in the valleys of Palpa, Peru". In: Reindel, Markus/Wagner, Günther A. (Hg.): New Technologies for Archaeology. Multidisciplinary Investigations in Palpa and Nasca, Peru. Heidelberg/Berlin: Springer-Verlag, S. 439-462.

Reindel, Markus

2010a "Archäologische Forschungen der Jahre 2007 und 2008 im Anden-Transekt, Süd-Peru”. In: Zeitschrift für Archäologie Außereuropäischer Kulturen, 3: 207-224.

Reindel, Markus (2010b): “Ausgrabungen und Forschungen der Kommission für Archäologie Außereuropäischer Kulturen, Bonn: Andentransekt (Peru)'. In: Archäologischer Anzeiger 2010 (2): 335-338.

Reindel, Markus

2012 "Archäologische Forschungen der Jahre 2009 und 2010 im Anden-Transekt, Süd-Peru”. In: Zeitschrift für Archäologie Außereuropäischer Kulturen 4: 370-384.

Reindel, Markus; Eitel, Bernhard

2012 "Der Natur auf der Spur: Klima-und Bevölkerungsgeschichte in den Anden“. In: Bundesministerium für Bildung und Forschung (Hg.): Neue Blicke auf alte Kulturen-Wechselwirkungen zwischen Natur- und Geisteswissenschaften in der Archäologie. Bonn, Berlin (2012): W. Bertelsmann Verlag. S. 9-11.

Reindel, Markus; Isla Cuadrado, Johny

2001 "Los Molinos und La Muña. Zwei Siedlungszentren der Nasca-Kultur in Palpa, Südperu. Los Molinos y La Muña. Dos centros administrativos de la cultura Nasca en Palpa, costa sur del Perú”. Beiträge zur Allgemeinen und Vergleichenden Archäologie, 21: 241-319.

Reindel, Markus; Isla Cuadrado, Johny

2006 "Culturas tempranas de la costa sur del Perú: sus evidencias en los valles de Palpa". In: Boletín de Arqueología PUCP 10: 237-284.

Reindel, Markus; Isla Cuadrado, Johny

2009 "El Período Inicial en Pernil Alto, Palpa, costa sur del Perú”. In: Boletín de Arqueología PUC, 13: 259-288.

Reindel, Markus; Isla Cuadrado, Johny; Lambers, Karsten (2006): "Altares en el desierto: las estructuras sobre los geoglifos de Palpa”. In: Arqueología y Sociedad 17: 179-222.

Reindel, Markus; Isla Cuadrado, Johny; Hecht, Niels; Kupferschmidt, Denise; Otten, Heike

2010 "La pala investigadora de Max Uhle. Sus aportes a la cronología de la costa sur a la luz de las investigaciones recientes". In: Kaulicke, Peter; Fischer, Manuela; Masson, Peter; Wolff, Gregor (Hg.): Max Uhle (1856-1944). Evaluaciones de sus investigaciones y obras. Lima: Fondo Editorial de la Pontificia Universidad Católica del Perú, S. 253-279.

Reindel, Markus; Stöllner, Thomas; Gräfingholt, Benedikt 2013 "Mining Archaeology in the Nasca and Palpa region, south coast of Peru". In: Tripcevich, Nicholas; Vaughn, 
Kevin J. (Hg.): Mining and Quarrying in the Ancient Andes: Sociopolitical, Economic and Symbolic Dimensions. New York: Springer. S. 299-322.

Schittek, Karsten; Forbriger, Markus; Schäbitz, Frank; Eitel, Bernhard

2012 "Cushion peatlands-fragile water ressources in the high Andes of southern Peru". In: Weingartner, Herbert; Blumenstein, Oswald; Vavelidis, Michalis (Hg.): WaterContributions to sustainable supply and use. Landscape and sustainable development. Vol. 4. Salzburg: Universität Salzburg, Fachbereich Geographie und Geologie. S. 63-84. Tripcevich, Nicholas; Contreras, Daniel A.

2011 "Quarrying evidence at the Quispisisa Obsidian source, Ayacucho, Peru". In: Latin American Antiquity, 22: 121-136.

Troll, Carl

1968 "The cordilleras of the tropical Americas. Aspects of climatic, phytogeographical and agrarian ecology". In: Colloquium geographicum, 9: 15-56. 
